\title{
The Perception of Patient Safety Culture among Physicians at an Academic Tu- nisian Hospital
}

\author{
Harizi $C^{\star 1,2,3}$, Bellali $\mathrm{H}^{1,2,3}$, Chelly $\mathrm{S}^{1}$, Hchaichi $\mathrm{A}^{1}$ and Chahed $\mathrm{MK}^{1,2,3}$
}

${ }^{1}$ Epidemiology and Biostatistics Department, Abderrahman Mami Hospital, Ariana, Tunisia

${ }^{2}$ Research Unit, Epidemiology and Biostatistics Department, Abderrahman Mami Hospital, Ariana, Tunisia

${ }^{3}$ Department of Epidemiology and Public Health, Faculty of Medicine of Tunis, Tunis-El Manar University, Tunis, Tunisia

*Corresponding author: Harizi C, Epidemiology and Biostatistic Department, Abderrahman Mami Hospital, 2080, Ariana, Tunisia, Fax: +216 70160 361, Tel: +216 97774 345, E-mail: chahidaharizi@hotmail.fr

Citation: Harizi C, Bellali H, Chelly S, Hchaichi A, Chahed MK (2020) The Perception of Patient Safety Culture among Physicians at an Academic Tunisian Hospital. J Public Health Hygiene Safety 1(1): 105. doi: 10.15744/2767-8792.1.105

Received Date: December 10, 2019 Accepted Date: December 18, 2019 Published Date: December 20, 2019

\begin{abstract}
Background: Patient safety has become a priority issue in health policy and healthcare management around the world. Assessing physician's attitudes about issues relevant to patient safety is the first stage of developing a safety culture. This study aimed to measure patient safety culture among physicians in Abderrahman Mami hospital, Ariana, Tunisia.

Methods: A cross-sectional descriptive study was conducted at the Abderrahman Mami hospital in Ariana during the month of October 2016. All the medical staff of all grades $(\mathrm{N}=140)$ was included. We used the validated French version of the "Hospital Survey on Patient Safety Culture" (HSOPSC) questionnaire. This questionnaire explored 10 dimensions of patient safety culture and 42 items. Responses were assessed with a 4-point Likert scale, ranging from "strongly disagree" to "strongly agree". For each dimension, an overall score was calculated from the percentages of positive responses for each item making up the dimension.

Results: A total of 132 physicians responded to our questionnaire. Two thirds of them were women. The mean age was $34 \pm 10$ years with extremes of 24 and 66 years. The percentage of positive responses in the various dimensions varied from $31.4 \%$ for "Management support for patient safety» to $81.9 \%$ for "Manager Expectations and actions promoting patient safety ", the only dimension Considered as developed (> 75\%). The overall safety score for care was $59.1 \%$.

Conclusion: Our study proved overall fairly average of patient safety culture among physicians working in A. Mami hospital. Treatment safety culture seems to be an area to develop in our hospital regarding these fairly average proved results.

Keywords: Patient Safety Culture; Perception; Medical Staff; Tunisia
\end{abstract}

\section{Introduction}

Patient safety has recently gained greater attention worldwide. One important indicator of patient safety is the rate of adverse events (AEs) among hospital patients. Several studies have shown the severity of these accidents, in terms of cost, frequency, and serious consequences [1-4]. The overall incidence of AEs among inpatients in various countries varies between 2 and 21\% [4,5]. However, between 35 and $70 \%$ of them have been judged preventable [4-6].

The 1999 report from the Institute of Medicine, USA, 'To Err Is Human', have revealed a substantial rate of AEs in hospital practice resulting in 44000 to 98000 deaths each year that could have been prevented [7]. This report brought a greater attention to the problem of patient safety and a growing Conviction that hospital staffs' ability to avoid harm will be better realized when a safety culture could be created [8].

Multiple studies found in literature have emphasized the importance of developing a patient safety culture as an effective approach to improve patient safety state such as the decrease in the length of stay and mortality $[9,10]$. However, the first step to start with in building safety culture is baseline assessment. In fact, assessing allows healthcare institutions to identify their strengths and weaknesses in terms of patient safety and to provide a clearer vision of the aspects that need attention.

In Tunisia, the health system is predominantly public. It is organized in three levels: primary level including primary healthcare centers (PHC) and Public district hospitals, secondary level including regional hospitals to which urban PHC facilities are linked and a third level composed from 22 university hospitals, which are mainly located in large urban cities. The public hospitals are relatively well distributed geographically in terms of physical facilities but remains facing challenges in terms of quality, access and performance [11]. 
Some studies were conducted to assess safety culture in Tunisian hospitals [12-14]. However, more studies are needed in this field and collaborative efforts must be combined to promote safety culture. Hence, this study was carried out to identify physicians' perceptions of patient safety at Abderrahman Mami hospital, in order to further guide strategies for a better safety culture improvement and a safer patient care.

\section{Methods}

\section{Study design}

A cross-sectional descriptive study was carried out with a medical staff at the university hospital Abderrahman Mami in Ariana during the month of October 2016. This is a hospital specializing primarily in the treatment of cardiopulmonary disease. It is considered as the referent center for respiratory tract disease in the country. It includes 21 services distributed as follows: 7 pulmonology services, one medical intensive care unit, one cardiology department, one oncology service, one cardiothoracic surgery service, one anesthesia services resuscitation, one emergency service, one dental service, one epidemiology service, pharmacy service and technical diagnostics platform (bacteriology laboratory, biology laboratory, pathology department, radiology department and a functional investigation service). It is a university hospital center with a hospital capacity estimated at 355 beds serving mainly the population of Greater Tunis and that of the northern part of the country. The hospital has 477 health professionals including 185 physicians, dentists and pharmacists.

\section{Study participants}

All medical staff exercising at Abderrahman Mami hospital was included, consisting of all the physicians, dentists and pharmacists $(\mathrm{N}=185)$ of all grades working in one of the 21 hospital inpatient services including residents and interns.

\section{Study instrument}

The current study used the French version of Hospital Survey of Patients' Safety Culture

(HSOPSC) questionnaire (Annex I) which was developed in 2004 by the American agency "Agency for Healthcare Research and Quality" (AHRQ) [15]. The HSOPSC has good psychometric properties, including item analysis, exploratory factor analysis, confirmatory factor analysis, and inter-correlation and reliability analysis [16]. The HSOPSC has also been translated into different languages and used in several other countries. The French version was validated by the team of the Coordination and Clinical Quality Assessment Committee in Aquitaine (CCECQA) [17]. It was choose to be used in our study since physicians master the French language, which is language of medical studies.

\begin{tabular}{|c|c|c|}
\hline Characteristics & Doctors & \\
\hline & $\mathrm{N}$ & $\%$ \\
\hline \multicolumn{3}{|l|}{ Gender } \\
\hline Male & 50 & 37.9 \\
\hline Female & 82 & 62.1 \\
\hline \multicolumn{3}{|l|}{ Age (years) } \\
\hline$<35$ & 82 & 62.1 \\
\hline $35-44$ & 31 & 23.5 \\
\hline$\geq 45$ & 19 & 14.4 \\
\hline \multicolumn{3}{|l|}{ Marital status } \\
\hline Single & 61 & 46.2 \\
\hline Married & 68 & 51.5 \\
\hline Divorced & 3 & 2.3 \\
\hline \multicolumn{3}{|c|}{ Work experience ( years) } \\
\hline$<1$ & 70 & 53 \\
\hline $1-5$ & 29 & 22 \\
\hline $6-10$ & 17 & 12.9 \\
\hline$>10$ & 16 & 12.1 \\
\hline \multicolumn{3}{|c|}{ Hours of work per week (hours) } \\
\hline$<40$ & 53 & 40.2 \\
\hline $40-59$ & 43 & 32.6 \\
\hline$\geq 60$ & 36 & 27.3 \\
\hline
\end{tabular}

Table 1: Sociodemographic and Professional Characteristics of Mami Hospital Doctors $(\mathrm{N}=132)$ (Ariana, Tunisia, 2016) 
The questionnaire covers two sections: demographic characteristics that included age, gender, marital status, grade, work area, years of work experience and hours of work a day. The other section was patient safety culture dimensions that explored 10 dimensions, composed of three to six items. This version of the questionnaire included 42 items of patient safety.

\begin{tabular}{|c|c|c|c|}
\hline Dimensions & $\begin{array}{c}\text { Overall } \\
\text { number (n) }\end{array}$ & $\begin{array}{l}\text { Negative re- } \\
\text { sponse (\%) }\end{array}$ & $\begin{array}{l}\text { Positive re- } \\
\text { sponse(\%) }\end{array}$ \\
\hline \multicolumn{4}{|l|}{ Overall perception of safety } \\
\hline We have patient safety problems in this facility & 132 & 45.5 & 54.5 \\
\hline It is just by chance that more serious mistakes do not happen around here & 131 & 66.7 & 33.3 \\
\hline Our procedures and systems are good at preventing errors from happening & 132 & 61.4 & 38.6 \\
\hline Patient safety is never sacrificed to get more work done & 132 & 62.9 & 37.1 \\
\hline \multicolumn{4}{|l|}{ Frequency of events reported } \\
\hline When a mistake is made, but is caught and corrected before affecting the patient, how often is this reported? & 131 & 63.8 & 36.2 \\
\hline When a mistake is made, but has no potential to harm the patient, how often is this reported? & 130 & 62.3 & 37.7 \\
\hline When a mistake is made that could harm the patient, but does not, how often is this reported? & 131 & 68.5 & 31.5 \\
\hline \multicolumn{4}{|l|}{ Manager expectations and actions promoting patient safety } \\
\hline My manager overlooks patients safety problems that happen over and over & 128 & 91.5 & 8.5 \\
\hline Whenever pressure builds up, my manager wants us to work faster, even if it means taking shortcuts & 128 & 78.5 & 21.5 \\
\hline Manager seriously considers staff suggestions for improving patient safety & 128 & 78.5 & 21.5 \\
\hline Manager says a good word when he/she sees a job done according to established patient safety procedures & 128 & 79.2 & 20.8 \\
\hline \multicolumn{4}{|l|}{ Organizational learning - continuous improvement } \\
\hline We are actively doing things to improve patient safety & 132 & 66.7 & 33.3 \\
\hline Mistakes have led to positive changes here & 132 & 79.5 & 20.5 \\
\hline After we make changes to improve patient safety, we evaluate their effectiveness & 131 & 52.3 & 47.7 \\
\hline We are given feedback about changes put into place based on event reports & 130 & 37.4 & 62.6 \\
\hline We are informed about errors that happen in the facility & 131 & 63.6 & 36.4 \\
\hline In this facility, we discuss ways to prevent errors from happening again & 132 & 74 & 26 \\
\hline \multicolumn{4}{|l|}{ Teamwork within units } \\
\hline People support one another in this facility & 132 & 74.2 & 25.8 \\
\hline When a lot of work needs to be done quickly, we work together as a team to get the work done & 132 & 78 & 22 \\
\hline In facility, people treat each other with respect & 132 & 82.4 & 17.6 \\
\hline Shift changes are problematic for patients in this facility & 131 & 80.2 & 19.8 \\
\hline When one area in this unit gets really busy, others help out & 132 & 48.5 & 51.5 \\
\hline \multicolumn{4}{|l|}{ Communication openness } \\
\hline Staff will freely speak up if they see something that may negatively affect patient care & 132 & 83.3 & 16.7 \\
\hline Staff feel free to question the decisions or actions of those with more authority & 131 & 52.7 & 47.3 \\
\hline Staff are afraid to ask questions when something does not seem right & 132 & 75.8 & 24.2 \\
\hline \multicolumn{4}{|l|}{ Non-punitive response to error } \\
\hline Staff feel like their mistakes are held against them & 131 & 47 & 53 \\
\hline When an event is reported, it feels like the person is being written up, not the problem & 131 & 61.4 & 38.6 \\
\hline Staff worry that mistakes they make are kept in their personnel file & 132 & 52.7 & 47.3 \\
\hline \multicolumn{4}{|l|}{ Staffing } \\
\hline We have enough staff to handle the workload & 132 & 31.1 & 68.9 \\
\hline Staff in this facility work longer hours than is best for patient care & 131 & 40.9 & 59.1 \\
\hline We work in 'crisis mode' trying to do too much, too quickly & 132 & 49.2 & 50.8 \\
\hline We use more agency/temporary staff than is best for patient care & 131 & 24.2 & 75.8 \\
\hline \multicolumn{4}{|l|}{ Management support for patient safety } \\
\hline Management provides a work climate that promotes patient safety & 132 & 30.3 & 69.7 \\
\hline The actions of management show that patient safety is a top priority & 132 & 21.2 & 78.8 \\
\hline Management seems interested in patient safety only after an adverse event happens & 132 & 35.9 & 64.1 \\
\hline Units work well together to provide the best care for patients & 132 & 38.2 & 61.8 \\
\hline
\end{tabular}




\begin{tabular}{|c|c|c|c|}
\hline Dimensions & $\begin{array}{c}\text { Overall } \\
\text { number (n) }\end{array}$ & $\begin{array}{c}\text { Negative re- } \\
\text { sponse (\%) }\end{array}$ & $\begin{array}{l}\text { Positive re- } \\
\text { sponse(\%) }\end{array}$ \\
\hline \multicolumn{4}{|l|}{ Teamwork across hospital } \\
\hline Things 'fall between the cracks' when transferring patients from one unit to another & 132 & 33.8 & 66.2 \\
\hline There is good cooperation among units that need to work together & 131 & 55.3 & 44.7 \\
\hline It is often unpleasant to work with staff from other units & 131 & 65.2 & 34.8 \\
\hline Problems often occur in the exchange of information across units & 132 & 48.5 & 51.5 \\
\hline
\end{tabular}

Table 2: Scores and Items of the Ten Dimensions of Safety Culture $(\mathrm{N}=132)$ (Ariana, Tunisia, 2016)

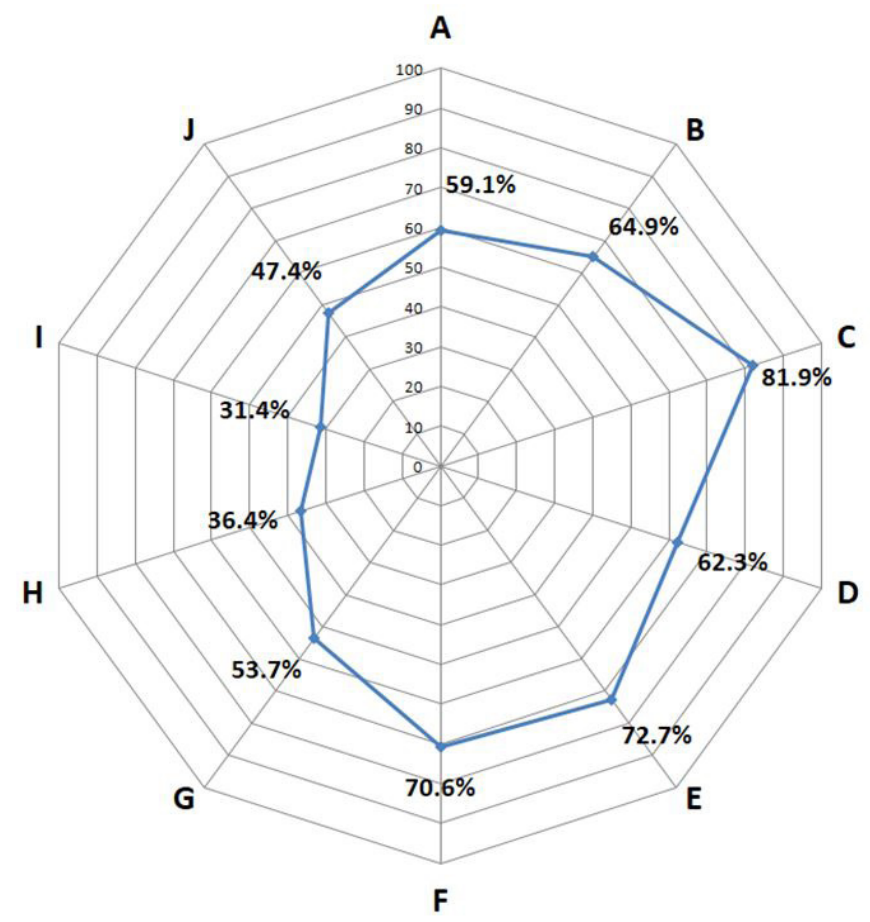

Figure 1: Spider Diagram Summarizing the Positive Responses in Relation to the Different Dimensions of the Patient Safety Culture (A) Overall perception of safety; (B) Frequency of events reporting; (C) Manager expectations and actions promoting patient safety; (D) Organizational learning - continuous improvement; (E) Teamwork within units; (F) Communication openness; (G) Non-punitive response to error; (H) Staffing; (I) Management support for patient safety; (J) Teamwork across hospital

The dimensions explored were (Annex I):

1. Overall perception of safety

2. Frequency of events reporting

3. Manager expectations and actions promoting patient safety

4. Organizational learning - continuous improvement

5. Teamwork within units

6. Communication openness

7. Non-punitive response to error

8. Staffing

9. Management support for patient safety

10. Teamwork across hospital

For each item related to safety dimensions, the personnel included in the study were asked to respond on a Lickert scale at 4 levels: $1=$ strongly disagree,

2 = disagree,

$3=$ agree,

$4=$ strongly agree 


\section{Data collection and ethical consideration}

At the beginning, we obtained Abderrahman Mami hospital ethics committee's approval and administrative authorizations from different departments' head chiefs via a written request where objectives and data collection methods were well informed. An anonymous self- administered questionnaire was then distributed to the participants after explaining them the study purposes and obtaining their verbal consent. Several visits to the participants were made on their workplaces to solicit their participation and encourage them to answer all items in order to limit missing data.

\section{Data analysis}

This study used SPSS 21.0 for Windows to perform the statistical analysis. First, descriptive statistics for facilities in our sample and descriptive statistics for each item on the HSOPSC were computed. Second, we calculated the proportions of positive responses and negative responses for each item. The responses "Strongly disagree" and "Disagree" were considered negative for patient safety, and the answers "Agree" and "Strongly agree" were considered positive. However, for questions that were formulated negatively, we reversed the quotations of the Likert scale to collect evenly scores of cultural dimensions of security. A safety culture dimension score was calculated. This score was the average percentage of positive responses by item. If this score was $75 \%$ or more of positive responses, the dimension is called developed. If it is between $50 \%$ and $74 \%$, the dimension is said to be improved and if it is below $50 \%$, the dimension is called undeveloped. Variables were presented using numbers and percent for qualitative variables; and mean and standard deviation for quantitative variables.

\section{Discussion}

Our study is one of the few studies carried out in the Tunisian health system. This study allowed our physicians to confront the concept of care safety, previously little known, and to analyze its observable and measurable dimensions. Indeed, the relatively high participation of physicians of all grades in this survey (71\%) demonstrates the increasing interest to safety culture. This responses rate was higher than those reported in several other studies $[9,10,18,19]$ which varied from $37 \%$ to $64.7 \%$.

The evaluation of the safety culture is the first step in the process towards its development. It is a diagnosis of the weak points found in the organization for the purpose of planning improvement actions [20]. In this context, it should be noted that research on the development of this culture is based on the assumption that improving the quality and safety of care passes through a welldeveloped safety culture among health professionals to minimize the number of adverse events [21]. Thus, improving the safety of care in any healthcare organization requires the implementation of a program whose first step would be to establish a diagnosis of situation: where we are now?

Through our study we were able to make this diagnostic of situation and describe the level of safety culture among physicians in our hospital. Except one dimension, we found low patient safety culture scores suggesting negative perception of most dimensions. Similar results were reported in Swedish hospitals [18]. Whereas, others studies in Kuwait and Taiwan [10,22] have found multiple areas of strength.

The lowest scores $(<50 \%)$ recorded in our study concerned the dimensions of "management support for patient safety "', Staffing" and" Teamwork across hospital ". Our results are consistent with other findings concerning specific areas of weakness [18,23]. The "management support for patient safety" was the lowest rated dimension in Swedish hospitals [18] and in some Tunisian ones [12,13], this finding suggests that the respondents believe top-level managers could do more to support patient safety. In fact, some of the patient safety challenges at the floor level cannot be solved without the management support; they need to be addressed at higher levels of the organizations.

\footnotetext{
"Manager Expectations and actions promoting patient safety" proved to be the most developed dimension with a score of $81.9 \%$. The review of the literature shows results close in Norway in 2010 with a score of 75\% [24] and in Sweden in 2019 with a score of 66.7\% [18]. On the other hand, in France in 2010, this dimension is the third among the smallest dimensions with a score of 48\% [25]. In Tunisia, this dimension was also developed with a score of $82.3 \%$ found by Bouafia et al. at the Farhat Hached University Hospital in Sousse [12]. Our work also concludes that $91.5 \%$ of respondents perceive that their immediate supervisors place importance on recurring patient safety problems in order to prevent them. This too strong score should be interpreted with caution. It can be explained by the fact that our physicians expressed their own expectations for the behavior of their superiors.

The second most developed dimension was “Teamwork within units" with a score of $72.7 \%$. The literature review shows that most of the published studies described teamwork within units as developed. An American study found a score of 80\% [26]. Similar results were reported in Lebanon, Saudi Arabia and Turkey with scores of 82.3\%, 84\% and 85\% respectively [27-29]. However, our results were comparable to those reported in the Belgian and French studies where the score for this dimension was less developed with $70 \%$ and $72.9 \%$ respectively [25,30]. For Tunisian studies, our score was better than that found in the study of Bouafia et al. (63.3\%) [12] and Ben Rejab et al. [13] and similar to that found in the study of Mallouli et al. [14], but this does not mean that this dimension is well developed, it still requires a major challenge to overcome.
} 
"Communication openness" dimension came in third place with a score of 70.6\%. It was considered a dimension to be improved since it had a score between $50 \%$ and $75 \%$. Although this score is higher than other national and international studies [12-14,24,26-28], this dimension requires more interest. Communication within and across hospital units is essential in an environment of care, especially as the patient is usually treated by several health professionals from different specialties [31]. It is shown that communication problems are the main contributors to adverse events. The quality and safety of care depends on the ability of health care providers to communicate well with patients and other health professionals [32]. It is therefore clear that communication difficulties can compromise patient safety.

As for the "Frequency of events reporting"', Organizational learning - continuous improvement " "overall perception of safety” and "non-punitive response to error", they had scores between $50 \%$ and $65 \%$, they are, thus, considered as dimensions to be improved. These results are almost in line with most published studies in this field.

The dimension of "non-punitive responses to error" had also a score of 53.7\%. This dimension had the lowest scores in several developing countries such as Saudi Arabia [28], Lebanon [27], Pure [33], Egypt [34] and turkey [29] with 22\%, 24.3\%, 30\%, 32\% and $32 \%$ respectively. It was also undeveloped at the national level $[13,14]$. Indeed, the declaration of the error, which is essential to achieve a culture of learning, can only occur in a non-punitive environment where adverse events may be reported without people being blamed. Thus, a change in culture based on blame and neglect from the point of view of other colleagues is necessary, providing a climate in which the health professional feels free to express him or her point of view. This will help address some problems threatening patient safety thus giving the opportunity to learn from these mistakes and avoid their reproduction.

In total with 9 dimensions out of 10 to be improved according to our results and according to other recent studies carried out in our country $[13,14]$, patient safety seems to be an axis of work to be developed in the Tunisian health system in general.

This present study presented some limitations. The first is the possibility of habitual reporting bias in this type of study, with overly positive responses from respondents for fear of stigmatization or for reasons of social desirability despite anonymity. However, this risk is lower relative to the risk associated with quantitative surveys based on face-to-face interviews [35].

The second limitation is related to the measuring instrument. Indeed, HSOPSC, although it is validated and used in several countries [22,36-39] does not allow to calculate an overall score of patient safety culture. In reality, the validation of such a score is complex and raises the problem of choosing the dimensions to be considered and their weights. Furthermore, so far no consensus or compromise on the number, content or denominator of the various dimensions making up the tools available for measuring patient safety culture is adopted [20]. Finally, this study was carried out in a single hospital, which limits the external validity.

\section{Conclusion}

Our study allowed us to have a diagnosis of the situation concerning the perception of the level of patient safety culture by the physicians in our establishment, which proved overall fairly average. It remains necessary to put in place an integrated approach with specific interventions to improve patient safety. This will necessarily involve the development of a culture based on trust, teamwork and non-punitive error reporting, all integrated within a goal of improving the quality of care and patient safety through better risk management in hospitals. This type of study should be extended to all others health professionals.

\section{References}

1. Roque KE, Tonini T, Melo EC (2016) Adverse events in the intensive care unit: impact on mortality and length of stay in a prospective study. Cad Saude Publica 32: e00081815.

2. Friedman CF, Clark V, Raikhel AV, Barz T, Shoushtari AN, et al. (2017) Thinking Critically About Classifying Adverse Events: Incidence of Pancreatitis in Patients Treated With Nivolumab + Ipilimumab. J Natl Cancer Inst 109: 10.1093/jnci/djw260.

3. Sousa P, Uva AS, Serranheira F, Uva MS, Nunes C (2018) P Patient and hospital characteristics that influence incidence of adverse events in acute public hospitals in Portugal: a retrospective cohort study. Int J Qual Health Care 30: 132-7.

4. Braiki R, Douville F, Ben Hasine A, Souli I (2019) Factors of reporting adverse events in a Tunisian hospital [Facteurs Liés Au Signalement Des Évènements Indésirables Associés Aux Soins Dans Un Hôpital Tunisien]. 31: 553-9.

5. Zegers M, de Bruijne MC, Wagner C, Hoonhout LH, Waaijman R, et al. (2009) Adverse events and potentially preventable deaths in Dutch hospitals: results of a retrospective patient record review study. Qual Saf Health Care 18: 297-302.

6. Michel P, Quenon JL, Djihoud A, Tricaud-Vialle S, de Sarasqueta AM (2007) French national survey of inpatient adverse events prospectively assessed with ward staff. Qual Saf Health Care 16: 369-77.

7. Kohn LT, Corrigan JM, Donaldson MS (2000) To Err is Human: Building a Safer Health System. National Academies Press, USA.

8. Mahjoub M, Fredj BS, Bouafia N, Bouriga R, Jalleb BN, et al. (2018) Promoting safety culture through health-care professional-patient relationship's improvement. Tunis Med 96: 135-41.

9. Sturm H, Rieger MA, Martus P, Ueding E, Wagner A, et al. (2019) Do perceived working conditions and patient safety culture correlate with objective workload and patient outcomes: A cross-sectional explorative study from a German university hospital. PLoS One 14: e0209487.

10. Ali H, Zenhom Ibrahem S, Al Mudaf B, Al Fadalah T, Jamal D, et al. (2018) Baseline assessment of patient safety culture in public hospitals in Kuwait. BMC Health Servi Res 18: 158.

11. Arfa C, Leleu H, Goaïed M, Mosseveld CV (2017) Measuring the Capacity Utilization of Public District Hospitals in Tunisia: Using Dual Data Envelopment Analysis Approach. Int J Health Policy Manag 6: 9-18. 
12. Bouafia N, Bougmiza I, Bahri F, Ezzi O, Ben Jalleb N, et al. (2014) Measuring the safety culture of care among doctors in a Tunisian hospital Public Health. Sante Publique 26: 345-53.

13. Ben Rejeb M, Chebil D, Merzougui L, Kacem B, Khefacha-Aissa S, et al. (2017) Patient Safety Culture in a Tunisian Teaching Tertiary Care Hospital. Arch Nurs Pract Care 3: 077-083.

14. Mallouli M, Aouicha W, Tlili MA, Ben Dhiab M (2018) Patient Safety Culture in Tunisia: Defining Challenges and Opportunities. Vignettes in Patient Safety 3: 78-88.

15. Sorra J, Gray L, Streagle S, Famolaro T, Yount N, et al. (2004) AHRQ Hospital Survey on Patient Safety Culture: User's Guide. AHRQ publication 04-0041.

16. Flin R (2007) Measuring safety culture in healthcare: a case for accurate diagnosis. Saf Sci 45: 653-67.

17. Occelli P, Quenon J-L, Kret M, Domecq S, Delaperche F, et al. (2013) Validation of the French version of the Hospital Survey on Patient Safety Culture questionnaire. Int J Qual Health Care 25: 459-68.

18. Danielsson M, Nilsen P, Rutberg H, Årestedt K (2019) A National Study of Patient Safety Culture in Hospitals in Sweden. J Patient Saf 15: 328-33.

19. Smits M, Keizer E, Giesen P, Tveter Deilkås EC, Hofoss D, et al. (2018) Patient safety culture in out-of-hours primary care services in the Netherlands: a crosssectional survey. Scand J Prim Health Care 36: 28-35.

20. Nascimento A (2011) Patient safety and safety culture: A review of the literature. Cien Saude Colet 16: 3591-602.

21. Occelli P, Quenon J-L, Hubert B, Hoarau H, Pouchadon M-L et al. (2007) The Health Safety Culture : a rapidly emerging concept. Risques \& Qualité en milieu de soins 4: 207-12.

22. Chen IC, Li HH (2010) Research Article Measuring Patient Safety Culture in Taiwan using the Hospital Survey on Patient Safety Culture (HSOPSC). BMC Health Serv Res 10: 152-62.

23. Wagner C, Smits M, Sorra J, Huang CC (2013) Assessing patient safety culture in hospitals Across countries. Int J Qual Health Care 25: 213-21.

24. Haugen AS, Softeland E, Eide GE, Nortvedt MW, Aase K, et al. (2010) Patient safety in surgical environments: cross-countries comparison of psychometric properties and results of the Norwegian version of the Hospital Survey on Patient Safety. BMC Health Serv Res 10: 279-89.

25. Santé HAdl (2011) Measuring the safety culture of care: survey of physicians engaged in accreditation. Journal de laccréditation des médecins $21: 4$.

26. Sorra J, Famolaro T, Dyer N (2012) Hospital Survey on Patient Safety Culture 2012 user comparative database report. (Prepared by Westat, Rockville, MD, under Contract No. HHSA 290200710024C). Rockville, MD: Agency for Healthcare Research and Quality. AHRQ Publication 12-0017: 69.

27. El-Jardali F, Jaafar M, Dimassi H, Jamal D, Hamdan R (2010) The current state of patient safety culture in Lebanese hospitals: a study at baseline. Int J Qual Health Care 22: 386-95.

28. Alahmadi H (2010) Assessment of patient safety culture in Saudi Arabian hospitals. Qual Saf Health Care 19: 1-

29. Teleş M, Kaya S (2019) Staff perceptions of patient safety culture in general surgery departments in Turkey. Afri Health Sci 19: 2208-18.

30. Hellings J, Schrooten W, Klazinga N, Vleugels A (2007) Challenging patient safety culture: survey results. Int J Health Care Qual Assur 20: 620-32.

31. World Health Organization (2007) Collaborating Centre for Patient Safety Solutions, Joint Commission International, Geneva, Switzerland.

32. King J, Anderson CM (2012) The Canadian interprofessional patient safety competencies: their role in health-care professionals' education. J Patient Saf 8: 30-5.

33. Arrieta A, Suárez G, Hakim G (2018) Assessment of patient safety culture in private and Public hospitals in Peru. Int J Qual Health Care 30: 186-91.

34. El-Sherbiny NA, Ibrahim EH, Abdel-Wahed WY (2020) Assessment of patient safety culture among paramedical personnel at general and district hospitals, Fayoum Governorate, Egypt. J Egypt Public Health Assoc 95: 4-12.

35. Szekendi MK, Barnard C, Creamer J, Noskin GA (2010) Using patient safety morbidity and mortality conferences to promote transparency and a culture of safety. Jt Comm J Qual Patient Saf 36: 3-9.

36. Arabloo J, Rezapour A, Ebadi Fard Azar F, Mobasheri Y (2012) Measuring Patient Safety Culture in Iran Using the Hospital Survey on Patient Safety Culture (HSOPS): an Exploration of Survey Reliability and Validity. Int J Hosp Res 1: 15-28.

37. Nie Y, Mao X, Cui H, He S, Li J, et al. (2013) Hospital survey on patient safety culture in China. BMC Health Serv Res 13: 228.

38. Bodur S, Filiz E (2009) A survey on patient safety culture in primary healthcare services in Turkey. Int J Qual Health Care 21: 348-55.

39. Gimenez-Marin A, Rivas-Ruiz F, Garcia-Raja AM, Venta-Obaya R, Fuste-Ventosa M et al. (2015) Assessment of patient safety culture in clinical laboratories in the Spanish National Health System. Biochem Med (Zagreb) 25: 363-76.

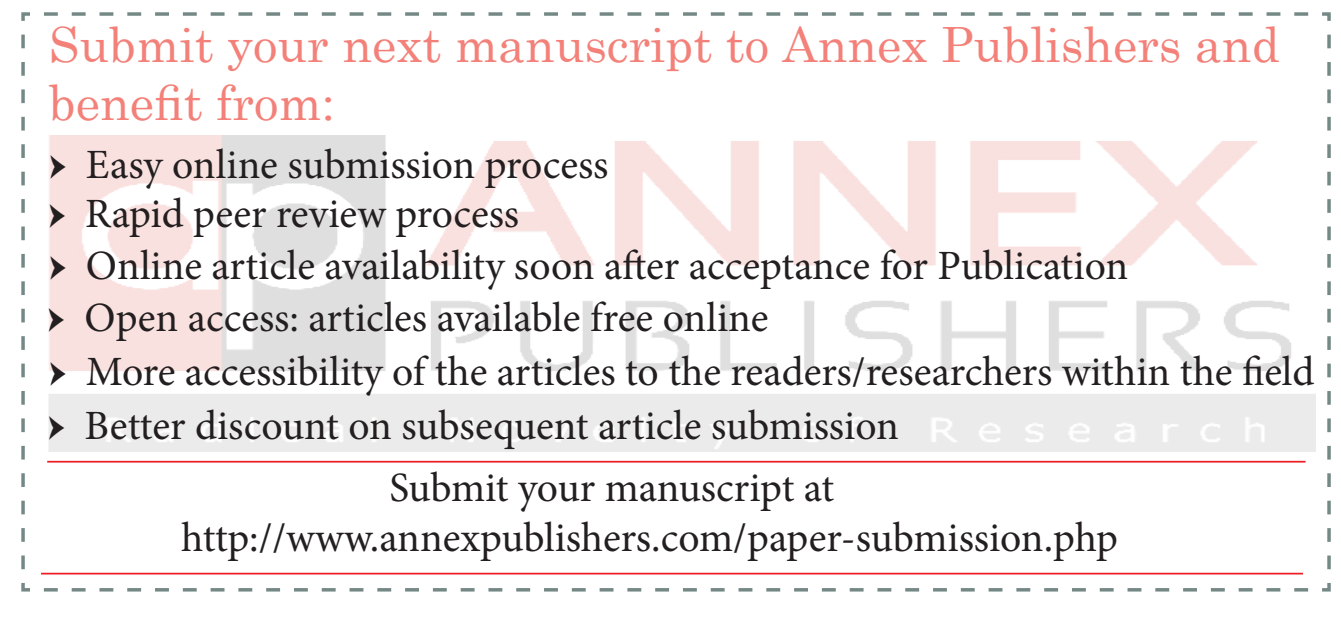

